\title{
ALTERAÇOES ESTRUTURAIS EM MANDIOCAS PRODUZIDAS COM DIFERENTES CONDIÇÕES DE COZIMENTO
}

\author{
L. T. GONÇALVES ${ }^{1 *}$, L. A. CAÉ ${ }^{1}$, S. J. FREITAS ${ }^{1}$, N. R. PEREIRA ${ }^{1 * *}$ \\ ${ }^{1}$ Universidade Estadual do Norte Fluminense Darcy Ribeiro, Laboratório de Tecnologia de \\ Alimentos, Centro de Ciências e Tecnologias Agropecuárias \\ e-mail:*1eticiatinoco@hotmail.com,**nadiar@uenf.br
}

\begin{abstract}
RESUMO
Durante o cozimento de alimentos ricos em carboidratos, como é o caso da mandioca, ocorrem alterações estruturais, provocadas pela penetração de água nos tecidos, que rompem as ligações entre cadeias dos carboidratos, criando camadas de hidratação das moléculas separadas. Essas alterações são provocadas pela gelatinização do amido, que acontece entre 45 e $80{ }^{\circ} \mathrm{C}$. Este trabalho estudou efeito do cozimento, com imersão em água, em fatias de mandioca e analisou as alterações provocadas nas diferentes condições de temperatura $\left(40\right.$ a $100{ }^{\circ} \mathrm{C}$ ) e tempo (2 a 10 minutos), determinando a melhor condição para posterior secagem. Os resultados mostraram que tanto a variável tempo como a variável temperatura influenciaram a umidade e a absorção de água das amostras após o cozimento. A utilização de $70{ }^{\circ} \mathrm{C}$ por 6 minutos no cozimento pode ser considerada como a condição mais apropriada para posterior processamento como secagem, pois nesta as amostras apresentaram cozimento suficiente evidenciado pela formação de gel superficial e não apresentaram quebra ou fissuras nas fatias.
\end{abstract}

\section{INTRODUÇÃO}

Durante o cozimento em presença de água, ocorrem alterações na textura de alimentos ricos em carboidratos provocados pela gelatinização do amido, que acontece entre 45 e $80^{\circ} \mathrm{C}$. A gelatinização do amido é definida como a destruição de ordem molecular dentro dos grânulos de amido. Esses grânulos são formados por uma mistura de dois polímeros: um polissacarídeo linear, chamado amilose, e um polissacarídeo ramificado, chamado amilopectina. As mudanças irreversíveis provocadas são: fusão dos cristais de amido, solubilização do amido, lixiviação dos grânulos de amido (amilose), absorção de água, inchaço do grânulo. Esses eventos são observados com a perda da birrefringência e aumento da viscosidade na suspensão. Essas alterações afetam os tecidos celulares, influenciando as características da massa apresentada após a cocção. Durante o cozimento, os grânulos de amido incham rapidamente, as moléculas de água penetram entre as cadeias, rompem as ligações entre elas e criam camadas de hidratação em torno das moléculas separadas. $\mathrm{O}$ amaciamento dos tecidos vegetais ocorre devido a alterações na parede celular com redução da força de adesão entre as células, que estão individualizadas e/ou rompidas (BOBBIO \& BOBBIO, 2001; BUTARELO, 2004; FELLOWS, 2006; ZHANG et al., 2013).

A gelatinização é influenciada por características do grânulo de amido como: composição, morfologia, arquitetura molecular, teor de amilose, cristalinidade e o peso molecular. A proporção água-amido determina a extensão da gelatinização. A gelatinização é considerada um processo em 
várias fases. Depois do inchaço das regiões amorfas, a estrutura do anel de crescimento começa a desintegrar-se e as regiões cristalinas sofrem fusão simultânea com um progressivo aumento da hidratação. Estruturalmente, os grânulos de amido são distribuídos em todo o corte dos vegetais e sua transferência de calor é dada em função de tempo e distância da fatia utilizada. Em uma dada espessura pode haver uma diferença na distribuição de calor. Essas diferenças de calor de distribuição são acompanhadas por diferenças no grau de gelatinização (NIJINTANG \& MBOFUNG, 2003; HUANG et al., 2009; FU et al., 2014).

A mandioca é um alimento de alto valor energético, utilizado como fonte de subsistência em várias regiões do mundo, mas sua alta perecibilidade após a colheita e a facilidade de contaminação microbiológica dificultam sua utilização na forma minimamente processada. O Brasil é hoje considerado o maior centro de diversidade de mandioca e o segundo maior produtor do mundo (EMBRAPA, 2005).

O presente trabalho tem como objetivo estudar uma das etapas da elaboração de chips de mandioca, que consiste do cozimento com imersão em água e analisar as alterações provocadas por diferentes tempos e temperaturas de cozimento na absorção de água, umidade e morfologia das amostras.

\section{MATERIAL E MÉTODOS}

\subsection{Preparo Da Matéria-Prima}

Foi utilizada a variedade de raiz de mandioca de mesa Espeto, proveniente de cultivo na Estação Experimental da UENFRJ, na ilha Barra do Pomba, no município de Itaocara, Rio de Janeiro, localizado na região Noroeste Fluminense. As raízes colhidas em setembro de 2014 e foram selecionadas de acordo com as condições de estrutura (tamanho e largura semelhantes) e cultivo (colhidas após 9 meses de plantio). As raízes foram lavadas, sanitizadas por imersão durante 15 minutos em solução de hipoclorito de sódio com $100 \mathrm{mg} / \mathrm{L}$ de cloro ativo. Em seguida, foram descascadas manualmente, cortadas em lâminas de $2 \mathrm{~mm}$ de espessura com auxílio de um fatiador de frios elétrico (Gural, modelo GLP-330, Paraná, Brasil) e depois em pedaços cilíndricos de $25 \mathrm{~mm}$ de diâmetro e $2 \mathrm{~mm}$ de espessura utilizando um cortador cilíndrico.

\subsection{Cozimento}

As amostras foram submetidas ao prétratamento, que consiste no cozimento do material por imersão em água destilada na proporção de 1:5 (amostra:água) em um bécker sobre chapa aquecedora (Fisatom, modelo 752A, série 188033, Brasil) com agitação manual, seguido de resfriamento em água destilada à temperatura ambiente (para interromper o cozimento) e escoamento do excesso de água em papel toalha.

O planejamento experimental fatorial $2^{2}$ com três repetições no ponto central foi realizado utilizando como variáveis independentes o tempo e a temperatura de cozimento, e como variáveis dependentes os teores de umidade e absorção de água, este pode ser observado na tabela 1 . 
Tabela 1 - Planejamento experimental fatorial $2^{2}$ proposto.

\begin{tabular}{ccccc}
\hline & \multicolumn{2}{c}{$\begin{array}{c}\text { Valores } \\
\text { codificados }\end{array}$} & \multicolumn{2}{c}{ Valores Reais } \\
\hline $\operatorname{Exp}$ & $\mathrm{T}$ & $\mathrm{t}$ & $\mathrm{T}(\mathrm{C}$ C) & $\begin{array}{c}\mathrm{t} \\
(\mathrm{min})\end{array}$ \\
\hline 1 & -1 & -1 & 40 & 2 \\
2 & +1 & -1 & 100 & 2 \\
3 & -1 & +1 & 40 & 10 \\
4 & +1 & +1 & 100 & 10 \\
5 & 0 & 0 & 70 & 6 \\
6 & 0 & 0 & 70 & 6 \\
7 & 0 & 0 & 70 & 6 \\
\hline
\end{tabular}

$\mathrm{T}=$ Temperatura $(\mathrm{C}), \mathrm{t}=$ tempo $(\mathrm{min})$.

\subsection{Umidade}

Foi utilizado o método 925.23 da AOAC (1995) para determinação da umidade. Três gramas das raízes cruas e cozidas foram utilizadas seguindo o método de secagem em estufa a $105^{\circ} \mathrm{C}$ até obter peso constante.

\subsection{Determinação Da Absorção De Água No Cozimento}

As amostras foram pesadas antes e após o cozimento, à temperatura ambiente, e a absorção foi determinada de acordo com a equação (1):

Absorção de água $(\%)=\frac{m_{A}^{c Z}-m_{a}^{i n}}{m_{a}^{i n}} \times 100$

Sendo que $m_{a}^{c z}=$ massa de água da amostra cozida; $m_{a}^{i n}=$ massa de água da amostra in natura.

\subsection{Estereoscopia}

Amostras de mandioca antes e após cozimento foram visualizadas em estereoscópio (Labomed, Luxeo 4D), com 90x de zoom. As imagens foram obtidas utilizando o programa Pixel Pro. Foram detalhadas as bordas, o centro, as fraturas e as paredes das amostras.

\subsection{Análise Estatística}

O presente trabalho foi analisado estatisticamente pela metodologia de superfície de resposta (BOX, HUNTER \& HUNTER, 1978), pelo programa estatístico STATISTICA 5.5.

\section{RESULTADOS E DISCUSSÃO}

$\mathrm{Na}$ tabela 2 estão apresentados os valores encontrados para porcentagem do conteúdo de umidade nas amostras in natura e cozida, seguindo o planejamento experimental.

Tabela 2 - Resultados de umidade (X) nas amostras in natura e cozidas.

\begin{tabular}{lll}
\hline $\mathbf{E x p}$ & $\boldsymbol{\%}_{\text {in natura }}$ & $\% \mathbf{X}_{\text {cozida }}$ \\
\hline $1(-1,-1)$ & $62,1 \pm 0,2$ & $68,5 \pm 0,3$ \\
$2(+1,-1)$ & $65,7 \pm 0,7$ & $72,8 \pm 0,4$ \\
$3(-1,+1)$ & $63,2 \pm 0,1$ & $71,7 \pm 0,3$ \\
$4(+1,-1)$ & $60,3 \pm 2,2$ & $78,8 \pm 0,2$ \\
$5(0,0)$ & $62,1 \pm 0,2$ & $72,8 \pm 0,3$ \\
$6(0,0)$ & $59,8 \pm 0,2$ & $70,3 \pm 0,5$ \\
$7(0,0)$ & $62,4 \pm 0,2$ & $74,5 \pm 0,9$ \\
\hline
\end{tabular}

Os teores médios encontrados para as amostras in natura variaram entre $59,8 \%$ e $65,7 \%$, estes valores estão semelhantes aos citados pela TACO (2011), onde relatam que a mandioca in natura apresenta $61,8 \%$. Já a mandioca cozida seguindo o planejamento experimental apresentou umidade final entre $68,5 \%$ e $78,8 \%$, esses valores são maiores ou iguais aos citados pela TACO (2011), nesta tabela os autores citam umidade após o cozimento de $68,7 \%$. 
Temperatura e tempo de cozimento mais elevados foram responsáveis por maior umidade dos pedaços, que pode ser observado quando comparado os experimentos 1 e 3 (40 $\left.{ }^{\circ} \mathrm{C}\right)$ com os experimentos 2 e $4\left(100{ }^{\circ} \mathrm{C}\right)$.

Na tabela 3 estão descritos os resultados de absorção de água de acordo com o planejamento experimental proposto.

Tabela 3 - Resultados encontrados para aumento de massa.

\begin{tabular}{cc}
\hline Exp & \% absorção de água \\
\hline $1(-1,-1)$ & 10,6 \\
$2(+1,-1)$ & 10,7 \\
$3(-1,+1)$ & 13,5 \\
$4(+1,-1)$ & 30,5 \\
$5(0,0)$ & 17,2 \\
$6(0,0)$ & 17,7 \\
$7(0,0)$ & 19,5 \\
\hline
\end{tabular}

De acordo com a tabela 2, é possível observar que a absorção de água pelas amostras de mandioca foi maior para temperaturas mais elevadas e tempos mais prolongados. No cozimento a $100{ }^{\circ} \mathrm{C}$ por 10 minutos foi obtido o maior resultado, a absorção de água foi de $30,5 \%$, esta mesma amostra apresentou o maior teor de umidade, de $78,8 \%$.

Quando o amido foi aquecido em excesso de água, a sua estrutura cristalina foi interrompida devido à quebra de ligações intra e intermolecular e ligações de hidrogênio. Subsequentemente, as moléculas de água formam ligações de hidrogênio com grupos hidroxila de amilose e amilopectina expostos o que resulta em aumento no inchamento do grânulo. O inchaço é o resultado da interação entre cadeias de amido dentro da região amorfa e cristalina. A extensão desta interação é determinada pelo teor de amiloseamilopectina e pelas características de teor em amilose e amilopectina em termos de peso molecular, distribuição, grau e comprimento da ramificação (FU et al., 2012).

FU et al. (2012) avaliando o poder de inchamento de amido de milho parcialmente gelatinizado (banho de água a 64, 66, 68, 69, 70 e $72{ }^{\circ} \mathrm{C}$ ) e seco por spray drying concluíram que quando a temperatura de aquecimento era superior a $60{ }^{\circ} \mathrm{C}$, o inchaço das amostras aumentou significativamente. Mas quando a temperatura de aquecimento variou de 70 a $90{ }^{\circ} \mathrm{C}$, não houve diferença significativa.

HUANG et al. (2009) observaram que os grãos de arroz embebidos a pressões e temperaturas mais elevadas absorveram mais água do que aqueles imersos em condições ambientais. Com relação à variação do volume verificaram que o volume aumentou significativamente, devido à água absorvida, com pressão e temperatura. $\mathrm{O}$ mecanismo dominante é o inchaço dos grânulos de amido localizados no interior das células do endosperma. Outro mecanismo também ocorre paralelamente, provocando o enchimento das fendas presentes no grão pela difusão de água e o seu posterior alargamento. A porcentagem do aumento de volume pode ser correlacionada com a absorção de umidade.

Os resultados da análise estatística obtida com os dados experimentais de umidade na amostra seca e absorção de água estão apresentados na tabela 4. Os efeitos foram estimados ao nível de significância de $10 \%$, sendo assim, a variável foi significativa estatisticamente quando $\mathrm{p} \leq 0,01$. 
Tabela 4. Estimativa dos efeitos sobre a umidade (X) e absorção água final das amostras de mandioca cozidas.

\begin{tabular}{|c|c|c|c|c|}
\hline & & Efeito & DP & $\mathbf{P}$ \\
\hline \multirow{4}{*}{$\mathbf{X}$} & Interação & 72,78 & 0,66 & 0,00 \\
\hline & $\mathbf{T}\left({ }^{\circ} \mathrm{C}\right)$ & 5,71 & 1,74 & 0,05 \\
\hline & $t(\min )$ & 4,63 & 1,74 & 0,08 \\
\hline & $\mathbf{T} * \mathbf{t}$ & 1,42 & 1,74 & $0,47^{*}$ \\
\hline \multirow{4}{*}{$\begin{array}{l}\text { Absorção } \\
\text { de água } \\
(\%)\end{array}$} & Interação & 17,11 & 0,62 & 0,00 \\
\hline & $\mathbf{T}\left({ }^{\circ} \mathrm{C}\right)$ & 8,62 & 1,63 & 0,01 \\
\hline & $\mathbf{t}(\min )$ & 11,37 & 1,63 & 0,01 \\
\hline & $\mathbf{T} * \mathbf{t}$ & 8,45 & 1,63 & 0,01 \\
\hline
\end{tabular}

A análise estatística de efeitos confirma que as variáveis temperatura e tempo apresentaram efeito significativo positivo, ou seja, quanto maior a temperatura e o tempo utilizados no cozimento maior foi o teor de umidade final. Quando utilizada temperatura por um menor tempo, as amostras apresentaram após o cozimento menor teor de umidade. Com relação à absorção de água todas as variáveis foram estatisticamente significativas, ou seja, quanto mais tempo e em maior temperatura as amostras ficavam imersas durante o cozimento, maior foi $o$ resultado da absorção de água, corroborando com os resultados de umidade.

Para verificação da validação do modelo estatístico, foi realizada a análise de variância (ANOVA). Nesta verificação foram eliminados os parâmetros não significativos. Foi verificada a variância da regressão e falta de ajuste ao nível de significância de $10 \%$. Foi utilizado o teste $\mathrm{F}$ para o planejamento experimental proposto cujos resultados estão apresentados na tabela 5 .
Tabela 5 - Análise da variância para as respostas umidade $(\% \mathrm{X}) \mathrm{p} \leq 0,01$.

\begin{tabular}{|c|c|c|c|c|c|c|}
\hline \multirow{2}{*}{$\begin{array}{l}\text { Fonte de } \\
\text { variação }\end{array}$} & \multicolumn{6}{|c|}{$\% X$ cozida } \\
\hline & SQ & GL & QM & Fcal & Ftab & $\mathrm{R}^{2}$ \\
\hline \multirow{3}{*}{$\begin{array}{l}\text { Regressão } \\
\text { Resíduo } \\
\text { Falta de } \\
\text { ajuste }\end{array}$} & 54,0 & 2 & 27,0 & 9,8 & 4,3 & 0,83 \\
\hline & 11,0 & 4 & 2,8 & & & \\
\hline & 2,2 & 2 & 1,1 & 0,3 & 9 & \\
\hline \multirow{2}{*}{$\begin{array}{l}\text { Erro puro } \\
\text { Total }\end{array}$} & 8,8 & 2 & 4,4 & & & \\
\hline & 65,1 & 6 & & & & \\
\hline \multirow{2}{*}{$\begin{array}{l}\text { Fonte de } \\
\text { variação }\end{array}$} & $\% \mathrm{~A}$ & bsorg & ão de & água & & \\
\hline & SQ & GL & QM & Fcal & Ftab & $\mathrm{R}^{2}$ \\
\hline \multirow{4}{*}{$\begin{array}{l}\text { Regressão } \\
\text { Resíduo } \\
\text { Falta de } \\
\text { ajuste }\end{array}$} & 275 & & & 34,3 & & \\
\hline & 0 & 3 & 91,7 & 4 & 5,39 & 0,97 \\
\hline & 8,0 & 3 & 2,7 & & & \\
\hline & 5,3 & 1 & 5,3 & 3,94 & 8,53 & \\
\hline Erro puro & 2,7 & 2 & 1,3 & & & \\
\hline Total & $\begin{array}{l}283, \\
0\end{array}$ & 6 & & & & \\
\hline
\end{tabular}

$\mathrm{SQ}=$ soma dos quadrados, $\mathrm{GL}=$ graus de liberdade, $\mathrm{QM}=$ média quadrática, Fcal e $\mathrm{F}$ tab $=$ valor de $\mathrm{F}$ calculado e tabelado respectivamente $\mathrm{e}$ $\mathrm{R}^{2}=$ coeficiente de determinação.

A análise estatística mostrou que o modelo utilizado para o teor de umidade e absorção de água foi significativo estatisticamente, ou seja, tem regressão significativa (Fcal > Ftab) e tem falta de ajuste não significativa (Fcal < Ftab). Os modelos, representado pelas equações 1 (umidade) e 2 (absorção de água), podem ser considerados preditivos, com coeficiente de determinação de 82 e $97 \%$, respectivamente.

$X(\%)=72,77+2,85 \times T+2,31 . t$

Absorção de água(\%) $=17,10+4,31 \times$

$T+5,68 \times t+4,22$ 
As imagens obtidas em estereoscópio podem ser observadas na figura 1 para as mandiocas in natura (a), cozida a $40{ }^{\circ} \mathrm{C}$ por 2 minutos (b), cozida a $70^{\circ} \mathrm{C}$ por 6 minutos (c) e cozida a $100{ }^{\circ} \mathrm{C}$ por 10 minutos (d).

Figura 1 - Imagens obtidas em esteroscópio. Mandiocas: in natura (a), cozida a $40{ }^{\circ} \mathrm{C}$ por 2 minutos (b), cozida a $70{ }^{\circ} \mathrm{C}$ por 6 minutos (c) e cozida a $100{ }^{\circ} \mathrm{C}$ por 10 minutos (d).

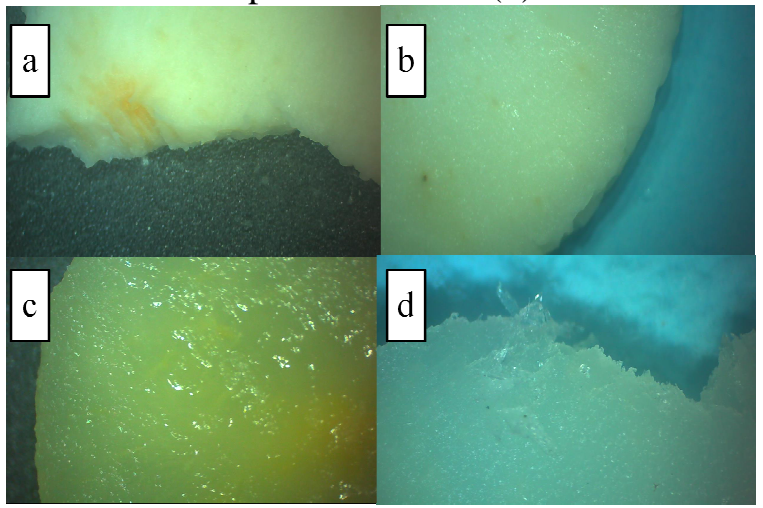

Observa-se, pelas imagens obtidas em estereoscópio, semelhanças entre as amostras in natura e cozidas a $40{ }^{\circ} \mathrm{C}$, pois nesta temperatura o cozimento da amostra foi brando, verificado pelo aspecto esbranquiçado das mesmas. Nesta temperatura não foram observadas alterações estruturais significativas. Com o cozimento a $70{ }^{\circ} \mathrm{C}$ (Fig1c), já se torna perceptível a gelatinização do amido e o cozimento da amostra, principalmente pelo brilho característico da formação do gel na superfície da amostra. Com o cozimento a $100{ }^{\circ} \mathrm{C}$, a amostra apresentou um cozimento uniforme, sem nenhum ponto esbranquiçado, confirmando os resultados de ganho de umidade das amostras após o cozimento em condições mais extremas de temperatura e tempo de imersão. Porém nesta condição do planejamento experimental, devido ao intenso amolecimento do tecido vegetal algumas amostras quebraram, dificultando posteriores análises e gerando perdas de amostras.

A melhor temperatura de cozimento estudada foi a de $70{ }^{\circ} \mathrm{C}$, nesta condição as amostras apresentaram gelatinização evidente, sem que a amostra quebrasse e material fosse perdido. Este produto cozido pode ser posteriormente seco, e nesta condição de temperatura possivelmente ocorreria mais aproveitamento do material e geraria um produto final mais atrativo ao consumidor.

Com os resultados das imagens foi possível visualizar a ocorrência de gelatinização do amido nas amostras cozidas a partir de $70{ }^{\circ} \mathrm{C}$. Essa gelatinização foi caracterizada pela formação de gel na superfície das amostras provocada pelo rompimento das membranas celulares nas fatias de mandioca.

\section{CONCLUSÃO}

Tanto a variável tempo como a variável temperatura influenciaram a umidade e a absorção de água das amostras após o cozimento. A utilização da condição intermediária do planejamento experimental ( $70{ }^{\circ} \mathrm{C}$ por 6 minutos) pode ser considerada mais apropriada, pois nesta condição as amostras apresentaram cozimento evidenciado pela formação de gel superficial e não fragmentaram como ocorreu com algumas amostras no cozimento a $100{ }^{\circ} \mathrm{C}$ por 10 minutos.

\section{NOMENCLATURA}

$\mathrm{X} \quad$ umidade

$\mathrm{X} / \mathrm{X}_{0}$ umidade adimensional

Aw atividade de água

ns não significativos

$\mathrm{T}$ temperatura $\left({ }^{\circ} \mathrm{C}\right)$

$\mathrm{T}$ tempo (min) 
SQ soma de quadrados

GL grau de liberdade

QM média quadrática

Fcal F calculado

Ftab F tabelado

$\mathrm{R}^{2} \quad$ coeficiente de determinação

\section{REFERÊNCIA}

AOAC. Official Mathods of Analysis. Washington: Association of Official Analytical Chemists, 1995.

BOBBIO, F.O.; BOBBIO, P.A. Introdução À Química De Alimentos. São Paulo: Varela, 2003.

BOX, G.E.P.; HUNTER, W.C.; HUNTER, J.S. Statistics For Experimenters: An Introduction To Design, Data Analysis And Model Building. New York: John Wiley and Sons, 1978.

BUTARELO, S. S.; BELEIA, A.; FONSECA, I. C. B.; ITO, K. C. Hidratação De Tecidos De Raízes De Mandioca (Manihot Esculenta Crantz.) E Gelatinização Do Amido Durante A Cocção. Ciência e Tecnologia de Alimentos, v.24, p.311-315, 2004.

EMBRAPA, Mandioca e Fruticultura Tropical. FARIAS, A.R.N. Processamento E Utilização Da Mandioca. Brasília: DF, 2005.

FELLOWS, P. J. Tecnologia do processamento de alimentos: princípios e práticas. Porto Alegre: Artmed, 2006.

FU, Z.; WANG, L.; ZOU, H.; LI, D.; ADHIKARI, B. Effects Of Partial Gelatinization On Structure And Thermal Properties Of Corn Starch After Spray
Drying. Carbohydrate Polymers, v.88, p.1319-1325, 2012.

FU, Z.; WANG, L.; ZOU, H.; LI, D.; ADHIKARI, B. Studies On The Starch-Water Interactions Between Partially Gelatinized Corn Starch And Water During Gelatinization. Carbohydrate Polymers, v. 101, p.727-732, 2014.

HUANG, S.; JAO, C.; HSU, K. Effects If Hydrostatic Pressure/Heat Combinations On Water Uptake And Gelatinization Characteristics Of Japonica Rice Grains: A Kinetic Study. Journal Of Food Science, v.74, p.442-448, 2009.

NIJINTANG, Y.N.; MBOFUNG, C.M.F. Kinetics Of Starch Gelatinisation And Mass Transfer During Cooking Of Taro (Colocasia Esculenta L. Schott) Slices. Starch, v.55, p.170-176, 2003.

TACO. Tabela Brasileira de Composição de Alimentos. Campinas, NEPA UNICAMP 2011.

ZHANG, Y.; HUANG, Z.; YANG, C.; HUANG, A.; HU, H.; GONG, A.; SUN, G.; HUANG, K. Material Properties Of Partially Pregelatinized Cassava Starch Prepared By Mechanical Activation. Starch, v.65, p.461468, 2013.

\section{AGRADECIMENTOS}

Os autores agradecem à FAPERJ pelo apoio financeiro e ao CNPq, CAPES e UENF pelas bolsas de estudo associados a este trabalho. 